\title{
The Role of Performances in Educational Practices: Experiences of BEd Students Preparing for the Classroom
}

\author{
Hetty Roessingh
}

\begin{abstract}
Performances and artefacts of student learning provide tangible evidence of their understanding of classroom instruction. Hattie $(2012,2015)$ uses the term visible learning to focus attention on the need for teachers to gather and consider these as evidence of students' ongoing learning, linking these tightly to teachers' pedagogical repertoire identified for having impact value. This article describes and illustrates a progression of learning tasks in an Initial Teacher Education (ITE) program that affords insights into students' beginning ability to complete and execute lesson plans in their first year, first semester of the program.
\end{abstract}

\section{Background}

In 2006 the Association of Canadian Deans of Education met for the first time to formulate broad principles on initial teacher education (ITE) to be applied across Canada in Faculties of Education. The broad domains of academic content knowledge, pedagogical knowledge, and situated practical knowledge, as well as an introduction to research and scholarship in education, underlie a framework of 12 principles aimed at preparing preservice teacher candidates (i.e., BEd students) for entry-level into our profession and setting the stage for their continuing professional development as in-service practitioners. In broad strokes, these principles encompass and align with the knowledge, skills, and dispositions we seek to engender in ITE programs.

Teaching is a complex, delicate juggling act that makes many demands of teachers. They must not only be good "on paper," but also good "on their feet" and teach from the heart (Palmer, 1997)—a fuzzy construct that is hard "to nail" and even tougher to evaluate in a preservice teacher candidate. Academic content knowledge is often expected in the admission requirements to ITE programs, especially among secondary route students. Pedagogical and situated practical knowledge thus become the core of what these programs do to prepare teachers of the future: this is the focus of this article. The broad question that frames this work relates to making visible through understanding performances, the skills and dispositions that are part and parcel of an ITE program.

My work takes place in a faculty of education located in a large, urban setting that prepares teachers who will overwhelmingly seek and find employment in the local school boards. I have teaching responsibilities in the undergraduate program that includes an on-campus survey course for first semester students newly admitted to our BEd degree and a field (school-based) component of one week in an elementary and one week in a secondary setting that affords the opportunity to make the connections 
between campus- and field-based experiences. It should be noted our work as teachers of teachers is second order pedagogy (Goodwin et al., 2014). However, there is an overlap of related content, pedagogical and practical knowledge, and skills. To a significant degree our faculty and ITE program seek to integrate knowledge and practice, by "walking the talk": that is, we want to model and engage our teacher-candidates in purposeful work that we hope they will observe in the field, and, in turn, adopt and adapt in their pedagogical repertoire for the own classrooms in the future.

This article describes a series of assignments in our ITE program that recognizes the value of learning by doing in the completion of a lesson plan, executing the plan via a micro-teaching assignment, the students' reflections, and instructor feedback. This work is completed in small collaborative learning groups that facilitate the give-and-take of discussion in constructing and theorizing the pragmatics of preparing to teach. In short, the path from pencil-and-paper planning to performing is made visible, documented, observed, interpreted, and used as "data" for the next iteration of my instructional planning (Helm, Beneke, \& Steinheimer, 1997). Artefacts of student learning are provided to illustrate this process.

\section{Three Domains of an ITE Program}

As mentioned above, ITE programs are structured to address three domains in preparing teacher candidates: academic content knowledge, pedagogical knowledge, and situated practical knowledge. In this section, further elaboration is provided for each domain.

Academic content knowledge, the "what" of teaching, is stipulated in provincial curriculum documents in content areas such as Mathematics, Sciences, Social Studies, and Literature. Among secondary route teacher candidates in particular, a high GPA in a previous degree in a relevant discipline is usually already in place and is a key factor in the admissions criteria to ITE (Casey \& Childs, 2011). Casey and Childs, however, conclude that GPA has little predictive value in determining students' preparedness for the eventual exigencies of the teaching profession. Hattie (2012) corroborates on this point, noting that teachers' subject matter knowledge does not improve student achievement.

Pedagogical knowledge, the "why" of teaching, addresses broad questions of developing the skills of teaching: lesson planning, task design, technique and strategy, grouping students for learning, and bringing to the fore the theoretical underpinnings that inform these aspects of teachers' work. For all teacher candidates, the meta-language of our discourse community in faculties of education and the teaching profession, is largely unfamiliar. Students of History, Literature, Physics, Mathematics, and Engineering, for example, must become conversant with the language of the predominant sociocultural theories and practices of teaching and learning that inform what we do as practitioners. Skills, theory, and the associated professional discourse conventions can be taught in an ITE program. However, we must be mindful that not all schooling contexts and parent communities adhere to the same foundational institutional frames associated with sociocultural theories and practices (Hirschkorn et al., 2017). For example, key findings evolving from a case study of perceptions of school culture and leadership in a local Chinese-Canadian bilingual program (Cheung, 2019) related to competing 
conceptualizations and expectations among staff and the parent community relating to concerns such as homework, disciplining children; the role of direct instruction, drill, rote learning, precision and accuracy required (i.e., 100\%) for basic written literacy development in Mandarin Chinese. Pen stroke and sequence matter in developing basic written literacy skills. This places the principal in the delicate position of constantly negotiating the curriculum, the pedagogical choices and the expectations of the parents, the Chinese-speaking staff, and the English-speaking staff.

Finally, situated practical knowledge represents the "how" question of enacting, executing, and evaluating the ability to mobilize content and pedagogical knowledge into the pragmatics of the teaching $\leftrightarrow$ learning equation and the crucial, conceptual essence of what it means to be present to and to engage our students- "to teach." It is an elusive dimension that is less amenable to instruction in an ITE program. It is on these points - the skills and dispositional dimension-that effective teachers make a difference (Hattie, 2012).

The scholarly community advocates for gleaning insights into students' learning through an array of approaches well beyond the traditional paper-and-pencil mode that has been the mainstay in education and teacher preparation for decades (Hattie, 2012, 2015; Perkins, n.d.). Some professions and career fields are more amenable than others to adjusting their instructional and assessment repertoire to fulfill this mandate: the performing arts; technical, vocational, and apprenticeship board programs such as welding, autobody, carpentry, culinary arts, aestheticians; and courses that involve design and production (e.g., dressmaking and fashion design come to mind). These disciplines provide a compelling argument for the central role of the hands in laying down the neuro-circuitry in the hand-brain complex, leading to embodied cognition and precision of execution that we want for our teacher candidates as well (Wilson, 1999, 2002). It is important to underscore this is more than "just technique" or pedagogical skill, though they do not replace basic knowledge and skills.

\section{The Role of Performances}

The question, "what is a performance task?" or more precisely, "what is an understanding performance?" has shifted the discussion from knowledge telling, to demonstrating understanding through the doing of some task that reflects deep understanding of the central conceptual information, procedural proficiency, and the concomitant executionary requirements, and finally, retrospective reflection. It must go beyond rote, routine doing, but demonstrate the "I got it!" dimension in the mold of Piagetian-type tasks (Beilin, 1992; Beilin \& Fireman, 1999) that ask children to arrange a set of sticks from shortest to longest, for example. Performances involve a representational view of understanding—students must manipulate and transform internalized schema into a product that reflects on the "I got it!" dimension. Achieving proficiency in complex tasks is incremental, making a good case for the inclusion of such an approach in any learning context. In time, with mindful practice, further feedback and ongoing reflection mastery may be achieved. 
Considerations for a performance task might include the authenticity of the task: is this something we would do in real life? The transferability from the classroom to real-world contexts, the explicitness and challenge presented in the learning goals, the degree of scaffolded supports built into the task are further considerations. Perkins (n.d.) explained the idea of flexible performance ability that involves online monitoring of the performance and the ability to correct, recuperate, and redirect the performance, if necessary, as in a jazz musical performance or a youngster making good use of their eraser in putting thought to words on the page. In a teaching context, it can mean recognizing a teachable moment (Baxter, 2007), that is, the ability to respond to an unplanned event during the day and to capitalize in the moment on a teaching opportunity. Strategy deployment might be another consideration, as when students are involved in debating a point, advancing an argument, or playing chess. Asking for student reflection of their performance can further their own understanding and growth.

Performance-based educational practices find their theoretical roots in the domains of experiential learning (Dewey, 1897), constructivism, and sociocultural theory (Vygotsky, 1978), with ongoing and evolving insights from the cognitive, and neurosciences. It is a practical theory of knowledge construction that emphasizes social and interactive processes, a continuity of experiences and experimentation in a purposeful learning environment. The role of the more knowledgeable other (MKO) in pitching learning experiences just beyond the current, actual level of development to challenge the learner in the zone of proximal development (ZPD: Vygotsky, 1978; 1962/1986), is crucial in scaffolding these next steps and mediating learning through language.

Making learning visible has been the watchword of educational movements both recent and past. Popularized by Hattie (2012), the term "visible learning" emphasizes the reciprocal relationship between teaching and learning. This is the intersection where effective teaching makes a distinct impact on student achievement outcomes. In the early childhood years, Helm et al. (1997) and Kline (2007), inspired by Malaguzzi's work in Reggio Emilia, similarly underscore basic underlying tenets of observing, documenting, and interpreting performances that apply to students in any learning context, including in a teacher preparation program, the context in which this work takes place. Helm et al. (1997) write:

Perhaps the greatest value of comprehensive documentation is its power to inform teaching. Teachers who have good documentation skills will make more productive planning decisions, including how to set up the classroom, what to do next, what questions to ask, what resources to provide and how to stimulate each child's development. The more information a teacher can gather when making these decisions, the more effective a teacher is likely to be. (p. 201)

Indeed, these instructional considerations apply equally well to an ITE program as becoming teachers are apprenticed into their responsibilities for instructional planning, and, in turn, their role in observing, documenting, and interpreting the impact of their practice on student learning outcomes in the classroom.

Our work as teachers of teachers includes modelling and making visible the types of learning that, in turn, and, in time, can have an impact in the classroom. It is important to our students' early preservice experiences that they can develop knowledge and skills for teaching in a safe, supportive, collaborative 
learning setting where mistakes are part of the learning process and risk-taking is encouraged. The stakes in the second semester (Field 2) are much higher, including the possibility of failure or withdrawal from the BEd program.

\section{A Progression of Understanding Performances in an ITE Program}

This section provides an illustrative example of a progression of understanding performances in our ITE program. These include a lesson plan following a Gradual Release of Responsibility (GRR) format, and a micro-teaching assignment that involves executing the lesson plan completed in groups. An individual reflection of the micro-teaching affords insights into each student's thoughts on the process. Finally, I, as the instructor, offer feedback on the micro-teaching.

\section{Lesson Planning: Templates as Scaffolds}

Many lesson plan templates are available, including suggestions from provincial Ministries. Some school boards mandate lesson plan templates, and commercially, an array of formats are on offer. Fisher and Frey (2013) advocate for an explicit, structured framework to teaching and learning: the GRR that draws on Vygotskian notions of modeling, guided practice, and independent practice, through a progression/continuity of three stages: "I do $\rightarrow$ we do $\rightarrow$ you do." This transitions the learner to ultimately work alone.

For the purposes of this assignment, I adapted Fisher and Frey's (2013) GRR lesson template to provide scaffolding and a reminder of the key concepts in the left-hand column. Recall these students are still preservice teachers, and they are just in week 3 of their ITE program. Students are expected to contextualize this plan with a topic of their choice, usually a craft or skill that can be taught to a class of 35 students, their classmates, within 15-20 minutes. Origami projects (i.e., cranes), making paper airplanes or friendship bracelets, performing a simple card or "magic trick," playing simple games (i.e., cat's cradle), gift wrapping a package, making occasion cards, or securing a men's tie have all been used in the past to very successfully realize the goal of asking students to prepare a lesson, and think about the use of materials, partial completion of the task with the material (if necessary, ahead of time) to save time, timing/pacing, scaffolding and more. 
Figure 1 illustrates the planning template.

GRADUAL RELEASE OF RESPONSIBILITY (GRR): LESSON TEMPLATE

\section{OPENING}

Teacher:

- Sets objective and purpose: 'invitational hook' - why is this important?

- Identifies goal: what should students know, be able to do?

- Establishes, connects and builds prior knowledge (P-K): metaphoric connection, new vocabulary, key concepts

- Technology use: Video clip?

Time:

Look 4s: 'Can do'/understanding performance in students:

I DO (Direct teaching and Modeling)

Teacher:

- Explains and demonstrates the use of materials, procedures, processes.

- Repeats the steps with a 'Think-aloud' to expose cognitive/

meta-cognitive engagement with the task

- Strategy used to teach?

- Models

- Anticipates 'challenge points' and focuses on what to do

- Scaffolds needed (hand-outs)

- Technology use (document projector?)

- Questions to 'check' for understanding

Time:
Look 4s:

WE DO (Guided instruction)

\section{Teacher:}

- Uses a variety of activities/steps to engage students (folding, creasing, gripping, working with materials)

- Checks for step by step progress

- Transitions to partner work

- Monitors and guides on timing, pacing

- Provides feedback, offers re-teaching

- Circulates, offers 1-1 support to help

Time:

\section{YOU DO (Independent work)}

\section{Teacher:}

- $\quad$ Circulates, monitors students work alone or in pairs

- Assesses student mastery of task

- Intervenes with anyone struggling learners

- $\quad$ 'Show and tell' time/gallery walk

Time:

\section{CLOSURE}

\section{Teacher:}

- Restates the purpose and goal of the lesson

- Informally assesses achievement ('exit slip') and invites student reflection

\section{Time:}

Fig. 1: Adapted GRR lesson template 
Figure 2 illustrates a lesson plan for making balloon animals/buddies, including the step-by-step process of putting the plan together, following the guidelines provided in left-hand column.

\section{GRADUAL RELEASE OF RESPONSIBILITY (GRR): LESSON TEMPLATE}

Teacher:

- Sets objective and purpose: 'invitational hook' - why is this important?

- Identifies goal: what should students know, be able to do?

- $\quad$ Establishes, connects and builds prior knowledge (P-K): metaphoric connection, new vocabulary, key concepts

- Technology use: Video clip?

Time:

\section{OPENING}

Objective: Students will create a balloon animal to sit on their wrist within twenty minutes. Students will improve their fine motor skills and listening comprehension.

Display sample balloon animal to class. 'This is what you are going to make.'

Hook: 'Does anyone remember receiving a balloon animal are going to make.'

Hook. 'Does anyone remember receiving a balloon animal at the fairground? Would you like to make a balloon animal for your child?

Logistics: We will split the class into 3 groups and each will be led by a facilitator. Within each group, the facilitator will go over each step to create our animal friends. We will also have a PowerPoint with each step being shown and animated. Encouragement: It's tricky at first, but with a bit of patience, you can master the technique. Each balloon animal is unique and no two will look alike Key Vocabulary: We will identify key terms we will use to refer to different parts of the balloon. We will label our hands 'dominant' and 'non-dominant.'

\section{DO (Direct teaching and Modeling)}

\section{Teacher:}

- Explains and demonstrates the use of materials, procedures, processes.

- $\quad$ Repeats the steps with a 'Think-aloud' to expose cognitive/

meta-cognitive engagement with the task

- Strategy used to teach?

- Models

- Anticipates 'challenge points' and focuses on what to do

- Scaffolds needed (hand-outs)

- Technology use (document projector?)

- Questions to 'check' for understanding

Time:
We will demonstrate how to make a balloon animal and then you will each make one with your group leader. Each step will be shown on the screen and there are examples provided of the animal at each stage of construction. Balloons are pre-inflated.

1. From the nozzle end of the balloon, measure out a length of 3 fingers width and twist at that measurement.

2. Hold the body of the balloon in your twisting hand and pinch the nozzle with your thumb and pointer finger of the same hand.

3. Use your other hand to twist the nozzle and neck together and loop nozzle through the created string.

4. Make four bubbles of two equal finger widths and twist the last bubble together with the head. Making sure to hold onto the previous made bubbles.

5. Measure the body length to be the same length as your legs and twist together.

6. Cut a hole in the end of the tail without letting go of your last bubble.

7. Loop the tail through the legs and then back around the head to create a bracelet.

8. Customize your animal with a sharpie.

9. Wear your new animal friend and show it off to your friends!

Think Aloud? Does it have to be a turtle? No! Get creative! 


\section{WE DO (Guided instruction)}

Teacher:

- Uses a variety of activities/steps to engage students (folding, creasing, gripping, working with materials)

- $\quad$ Checks for step by step progress

- Transitions to partner work

- Monitors and guides on timing, pacing

- Provides feedback, offers re-teaching

- Circulates, offers 1-1 support to help

Time:
- Make sure to push the air up from the balloon, into the uninflated nozzle, as you make each bubble. This will stop your balloon from popping.

- Remember to twist each bubble 10 times to make it secure.

- Do not skip a step as your animal friend will not be complete.

- $\quad$ Be bold with your twists! You might think as you twist your balloon that it's going to pop, but no, the balloons are surprisingly versatile!

Encouragement: Each animal friend will take time to make, so have patience and remember to have fun! It will take some practice to get all the steps right, but you can always re-do a step or untwist a section to make sure it's correct. Monitor/Assess Answer any questions - refer students to the supplementary resources.

If you have finished a step or completed your animal friend, check on a neighbor and see if they need help. Can you think of another way of explaining this?

\section{YOU DO (Independent work)}

\section{Teacher:}

- Circulates, monitors students work alone or in pairs

- Assesses student mastery of task

- Intervenes with anyone struggling learners

- $\quad$ 'Show and tell' time/gallery walk

Time:
Facilitators ensure members of their group have completed all the stages of balloon animal construction. Offering help to those individuals who need it. If necessary, they will assist other groups to finish their balloon animal sculptures. Students personalise their balloon animals with a permanent marker. Designs will be shown on the PowerPoint and models for inspiration.

The internet can be used if more inspiration is needed - for other creatures, etc.

What other animals can they make from balloons?

Displaying their animals on their wrists to friends and/or family.

Making up a story to go alongside their animal.

Balloon sculptures are displayed on a table for all to admire.

\section{CLOSURE}

\section{Teacher:}

- Restates the purpose and goal of the lesson

- Informally assesses achievement ('exit slip') and invites student reflection

Time:
Restate objective: 'You have all successfully created a balloon creature!'

Class discussion and informal assessment: This can take place around the display of balloon animals.

How successful do you think you were?

What was surprising?

What was difficult?

What was easier than you expected?

Did you perform better then you expected?

Did you enjoy it?

What other animals would you like to make?

Fig. 2: Completed lesson plan template

Our class then conducted a gallery walk of the lesson plans that afforded the opportunity to provide visual support for how the lesson would unfold to accompany the lesson plan template. This provides further evidence of the student group's thinking related to task progression, the demands of the micro-teaching, and the likely visual support in the demonstration phase that would ensure success of 
the lesson. It also reinforces the language used for the step-by-step progression in the plan. While this might seem like a simple consideration, these skills and insights need to transfer to the real-life context of the classroom in their Field 2 experiences when ITE students are expected to take on major responsibility for work in their placement schools.

More immediately, however, these students will be immersed in a Field 1 experience, as mentioned earlier (one week in each an elementary and secondary setting). The expectation here is that our students will be good ethnographers, embedding themselves into the culture of local schools and classrooms. These initial few weeks in the ITE program intend to provide frameworks, essential/inquiry questions for daily observations, documenting and interpreting in light of the research and campus experiences so far. This includes lesson planning in relation to curriculum, pedagogical and practical skills, formative assessment strategies, and the impact of all of these decisions on student learning. It's a very busy time for our students! Note taking becomes note making, that is the transformative dimension of making meaning of their journaling throughout the day in a supportive, collaborative cohort model that encourages talk and interaction. Students report even after day 1 the rich learning opportunity that Field 1 provides.

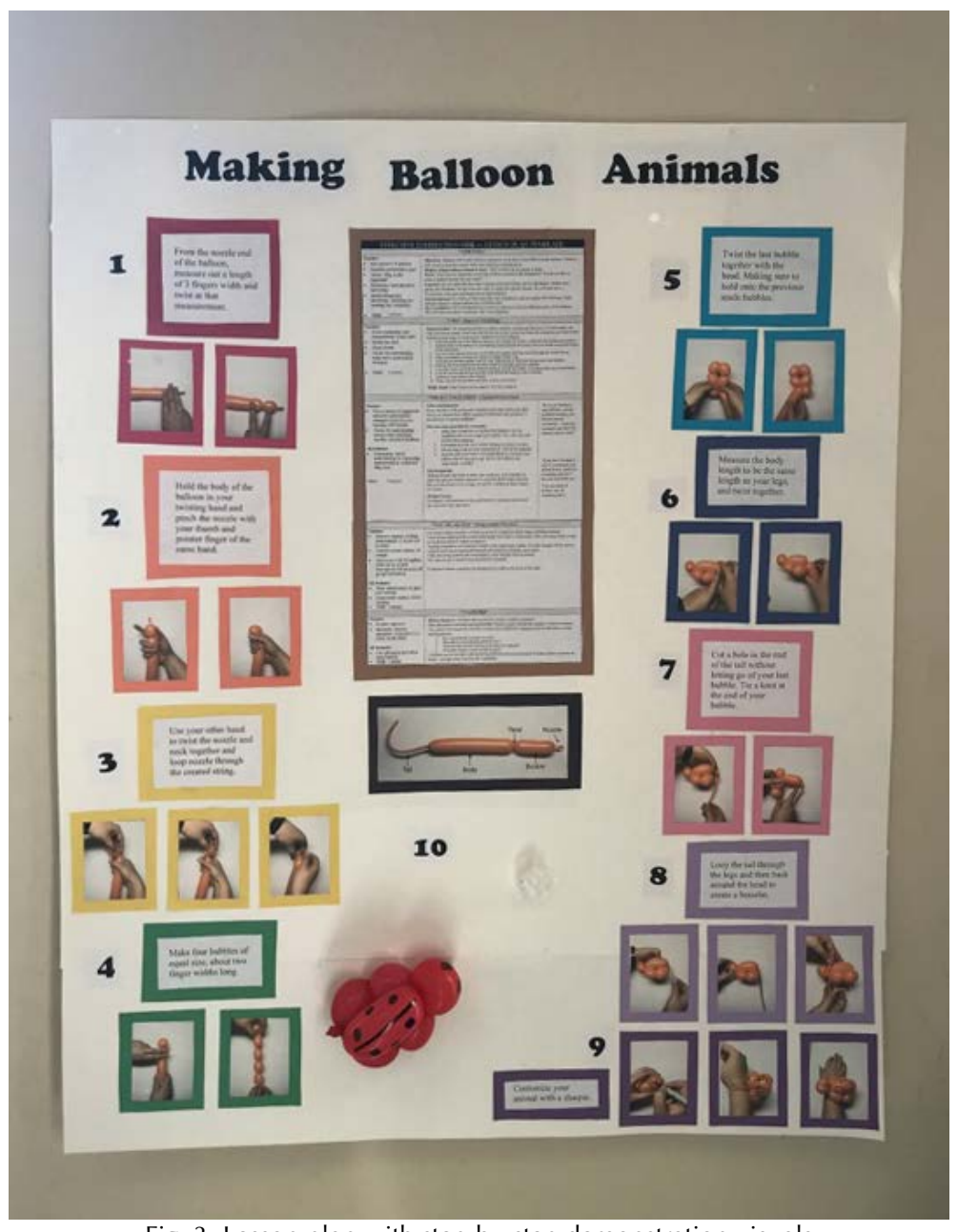

Fig. 3: Lesson plan with step-by-step demonstration visuals 


\section{Micro-Teaching: Executing the Lesson Plan}

Following this lesson plan assignment, students execute the lesson plan as a micro-teaching assignment. As a group of six, there was enough to do, especially since the balloon buddy project required a significant amount of prep work. The task is fairly challenging, and all six group members had to be proficient to engage the class. Distributing materials, demonstrating through multimodal inputs (demonstration both at the front of the class, and with the document projector), further support in the way of a handout, individual helping, circulating, offering feedback, and more all made this lesson very effective and a good learning experience for the group.

The class is invited to give informal feedback along the lines of the following rubric:

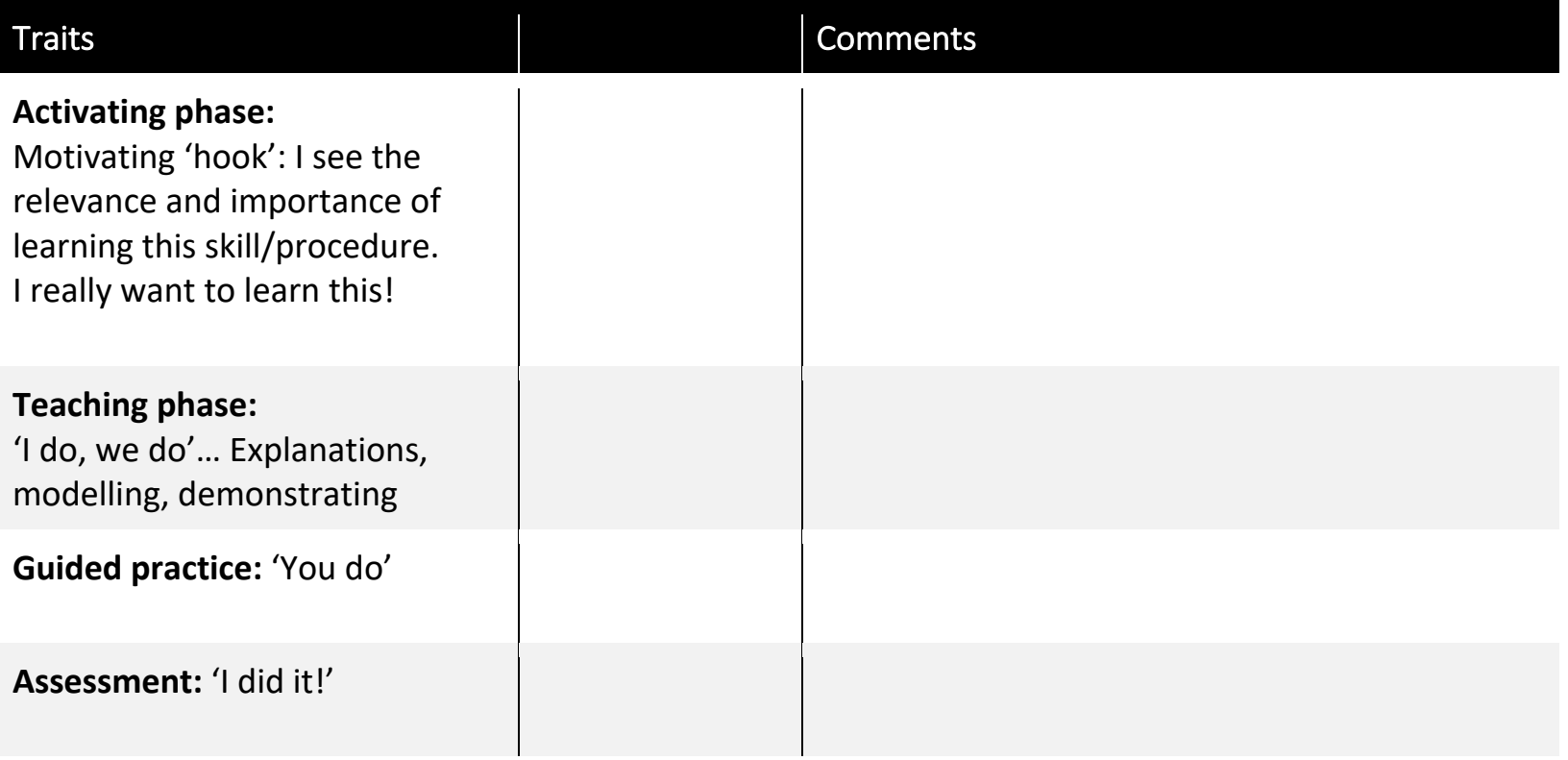

Fig. 4: Informal feedback slip for group teaching: So you think you can teach!

All six students further needed to submit a reflection of their lesson execution. Common themes emerging from these included the detailed thought, anticipation concerning the level of challenge, advance preparation, demonstration and modeling, pacing and timing, and more. They focus on the ideas of hands-on, a progression or continuity of step-by-step tasks toward a goal, multi-model inputs, scaffolds, and external memory supports (i.e., handouts). What became clear to me as the instructor in this feedback loop is the benefit of the template as a scaffold in itself that facilitates thoughtful lesson planning.

The evaluation and feedback for this progression of assignments focuses on three dimensions of the micro-teaching: delivery, engagement, and assessment. We hope to note initial ITE students' appropriating the language/terminology that connects to the pedagogical decisions they are beginning to make, their sense of confidence and teacher presence-this elusive dimension that is so difficult to articulate, but we "know it when we see it" phenomenon. 
Figure 5 provides the student group with a narrative assessment following a rubric on delivery, engagement, and assessment of their teaching performance.

\section{Lesson: Balloon buddy}

\section{Delivery: "hook," shared responsibilities, pacing}

A LOT of planning, prepping of materials, and rehearsal/practice was evident. This all allowed for a smooth delivery, with all group members participating. The class was quickly put to work once the demo/modelling/explanation phase was done. The balloons had been prepared/partially inflated and distributed to ensure quick entry into the task itself. This was a multi-step project where, at several spots, things could easily get derailed (you don't hold the nozzle properly, you don't twist enough or consistently in the same direction at each joint, you don't squeeze enough) — a good idea to provide enough challenge and keep the class working toward a doable goal within the allotted time.

Individualizing our balloon buddy and doing the gallery walk allowed for a progression of activities, sharing, and some fun.

\section{Engagement: Instructional strategies, multiple entry points/multi-model input, interaction with materials, interaction with teaching/group, individual helping / "teacher presence"}

Used various ways/multi-model input for modeling the process, including verbal, visual, and "hands on" help to get the grip and twist of the balloon just right, and the progression. The overhead projector/document projector was used effectively together with a handout as a permanent external memory support for following the multiple steps to the end point. All group members circulated to help with finger/hand positioning and finalizing the balloon buddy to make the wrist band; and then to personalize it with a marker pen-too fun, too cute. The gallery walk was a good way to get people moving past each other ... everything done within about the amount of time we wanted for this. Everyone in the group demonstrated confidence, exuded enthusiasm for the balloon buddy mini-project, and a strong sense of "teacher presence."

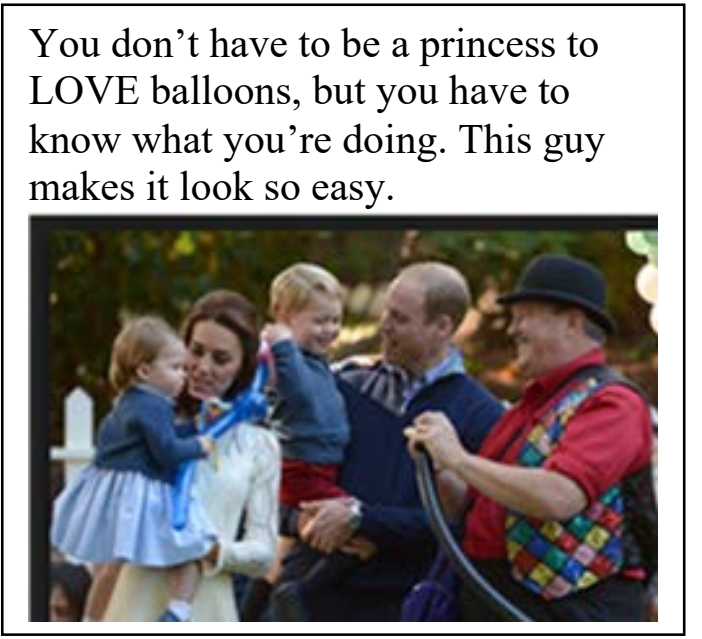

\section{Assessment: ongoing/progressive monitoring}

Group members circulated throughout to make sure everyone was on track and progressing smoothly with their balloon buddy, and when ready, to move to the second step of working with the marker pens to give their buddy a bit of a personality. This step yielded turtles, ladybugs, and all kinds of cute critters a kid could have close at hand for comfort and companionship. This would be a great party skill to have! Thank you so much for taking this assignment seriously, to thinking it through so meticulously and thoroughly and doing all the prepping ahead of time. It really came through! All of these are such important considerations for thinking about the classroom and working with kids of ALL ages, but little ones especially. They will not be patient without a good plan for working with and distributing materials, following multi-step tasks, transitioning from pair work to larger group gathering ... this could so easily collapse into chaos.

Fig. 5: Narrative assessment from instructor 


\section{Conclusion}

Preparing teachers for the future is a difficult task for ITE programs. Many competing and complex factors must be taken into consideration. A partial list of these might include:

- Linguistic and cultural diversity

- Honoring Indigenous ways of knowing and being in the world

- The call for inclusionary / least restrictive learning settings for all students

- Inquiry driven pedagogy balanced with explicit teaching of foundational skills

- The heightened demands for accountability concomitant with heightened demands for academic literacy for future participation in the knowledge economy

- The introduction of technology and increased expectations for digital literacy and engagement in distance delivery modes

- Character education

- Bilingual settings that may not conceptualize learning within a constructivist/sociocultural frame (Cheung, 2019)

ITE programs are under enormous pressure to recognize, recruit, select, and prepare teachers for the complexities and competing demands of the contemporary classroom. Current fiscal restraint experienced in many jurisdictions at all levels of education-both k-12 and postsecondary settingsplaces additional pressure to prepare and retain excellent teachers. It is a not a neat and tidy affair to select a cohort of ITE candidates from the pool of applicants, and respond to the local, national, and international workplace needs of our profession.

ITE programs, nevertheless, are charged with the responsibilities at a minimum of developing the pedagogical knowledge and skills that can make a difference at the classroom level. Performances and demonstrations of pedagogical knowledge and situated practical skills hold potential in our instructional and assessment repertoire in an ITE program. As for the elusive "it" factor that separates great teachers from good teachers, it resides in the heart and is of a piece of those who see teaching not as a career, or even a profession, but rather, a calling "to teach."

\section{References}

Association of Canadian Deans of Education (2006). Accord on initial teacher education. Retrieved from http://www.csse-scee.ca/docs/acde/acde_teachereducationaccord_en.pdf

Baxter, S. (2007). Teachable moments. Retrieved from

http://aplaceofourown.org/question_detail.php?id=101

Beilin, H. (1992). Piaget's enduring contribution to developmental psychology. Developmental Psychology, 28(2), 191-204. Retrieved from https://pdfs.semanticscholar.org/d188/2837e2f3de46e89e76a5a46a3330ca700e2d.pdf

Beilin, H., \& Fireman, G. (1999). The foundation of Piaget's theories: Mental and physical action. Advances in Child Development Behavior, 27, 221-246. 
The Role of Performances in Educational Practices: Experiences of BEd Students Preparing for the Classroom

Casey, C., \& Childs, R. (2011). Teacher education admission criteria as a measure of preparedness for teaching. Canadian Journal of Education, 34(2), 3-20. Retrieved from

http://journals.sfu.ca/cje/index.php/cje-rce/article/view/876

Cheung, C. (2019). Chinese-Canadian Bilingual Program: Perceptions of school culture and leadership. EdD Dissertation. Werklund School of Education, University of Calgary.

Dewey, J. (1897). My pedagogic creed. The School Journal, LIV(3), 77-80. Retrieved from http://www.infed.org/archives/e-texts/e-dew-pc.htm

Fisher, D., \& Frey, N. (2013). Better learning through structured teaching. A framework for the gradual release of responsibility (2nd ed.). ASCD. Retrieved from

http://www.ascd.org/publications/books/113006/chapters/Learning,-or-Not-Learning,-in-School.aspx

Goodwin, A., Smith, L., Souto-Manning, M., Cheruvu, R., Ying Tan, M., Reed, R., et al. (2014). What should teacher educators know and be able to do? Journal of Teacher Education, 64(4), 284-302.

Retrieved from http://jte.sagepub.com/content/65/4/284.full.pdf + html

Hattie, J. (2012). Visible learning for teachers: Maximizing impact on learning. Routledge. Retrieved from http://thequohaslostitsstatus.weebly.com/uploads/5/4/2/3/54231535/_visible_learning_for_teachers.pdf

Hattie, J. (2015, October 28). We aren't using assessments correctly. Retrieved from http://www.edweek.org/ew/articles/2015/10/28/we-arent-using-assessments-correctly.html

Helm, J., Beneke, S., \& Steinheimer, K. (1997). Documenting children's learning. Childhood Education, Summer, 1997, 200-205. Retrieved from https://doi.org/10.1080/00094056.1997.10521093

Hirschkorn, M., Sears, A., Sloat, E., Christou, T., Kristmanson, P., \& Lemisko, L. (2017). The relevance of prior learning in teacher education admissions processes. IN Education, 23(1). Retrieved from https://ineducation.ca/ineducation/article/view/256/923

Kline, L. (2007). Documentation panel: The 'making learning visible' project. Journal of Early Childhood Teacher Education, 29(1). Retrieved from https://doi.org/10.1080/10901020701878685

Palmer, P.J. (1997). The heart of a teacher identity and integrity in teaching. Change: The Magazine of Higher Learning, 29(6), 14-21. Retrieved from https://doi.org/10.1080/00091389709602343

Perkins, D. (n.d.). What is understanding? Chapter 2. Retrieved from https://psych.unl.edu/psycrs/974/TFU.pdf

Vygotsky, L. (1962/1986). Thought and language. (A. Kozulin, Translation). MIT Press. Retrieved from http://s-f-walker.org.uk/pubsebooks/pdfs/Vygotsky_Thought_and_Language.pdf

Vygotsky, L.S. (1978). Mind in society: The development of higher psychological processes. Harvard University Press. Retrieved from http://www.unilibre.edu.co/bogota/pdfs/2016/mc16.pdf

Wilson, F. (1999, October). The real meaning of hands-on education. Waldorf Research Bulletin, 2-12. Retrieved from http://pyrites.org/publications_files/Hands\%20on\%20Education.pdf

Wilson, F. (2002). Hand-made minds in the "digital" age. Conference address, June 21, 2002. Retrieved from http://www.handoc.com/HandmadeMindsInTheDigitalAge_FW_ConferenceAddress_2002-June-21.html 


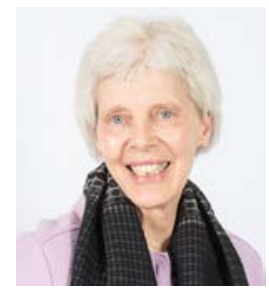

Hetty Roessingh is a long-time ESL practitioner in the K-12 system, and a faculty member (since 2000) in the Werklund School of Education, University of Calgary. Research interests have included language and literacy development and longitudinal tracking studies to note how academic vocabulary is learned over time. Of particular interest is how young learners come to "own" the words they know, as this is visible in their written literacy efforts beginning at the onset of literacy learning. For the past six years, Hetty has voluntarily tutored four young Punjabi speakers every Monday evening. She learns and finds inspiration in their energy, curiosity, and endless enthusiasm to learn language. 